\title{
ENRAIZAMENTO DE ESTACAS LENHOSAS DE CULTIVARES DE MARMELEIRO (Cydonia oblonga) TRATADAS COM FLOROGLUCINOL
}

\author{
LEO RUFATO ${ }^{1}$, GERALDINE DE ANDRADE MEYER ${ }^{2}$, \\ VALMOR JOÃO BIANCHI ${ }^{1}$, JOSÉ CARLOS FACHINELLO ${ }^{3}$
}

\begin{abstract}
RESUMO - O marmeleiro pertence à família Rosaceae. Atualmente, tem sido utilizado como porta-enxerto de pereira devido sua característica ananizante. O floroglucinol é um composto fenólico, potencializador da auxina. O presente trabalho foi conduzido em telado com nebulização intermitente e teve como objetivo avaliar a capacidade de enraizamento de estacas lenhosas de marmeleiro, tratadas com floroglucinol (zero, 1500 e $3000 \mathrm{mg} . \mathrm{L}^{-1}$ ), para indução de raízes. As cultivares testadas foram Pineapple, Meliform, Alongado, Radaelli, Portugal, Inta e MC. As estacas foram preparadas com $12 \mathrm{~cm} \mathrm{e} 1 / 2$ folha na parte superior, acondicionadas em caixas plásticas contendo vermiculita média. O delineamento utilizado foi o de blocos ao acaso, em arranjo fatorial ( $3 \times$ 7$)$, com 3 repetições e 5 estacas por parcela. As variáveis analisadas foram percentagem de enraizamento, número de raízes e percentagem de estacas brotadas. Observou-se que, independentemente da concentração testada, o floroglucinol não promoveu a indução do enraizamento de estacas lenhosas. A cultivar MC apresentou melhor percentagem de enraizamento, número de raízes e percentagem de estacas brotadas.
\end{abstract}

Termos de indexação: propagação, estaquia, porta-enxerto, enraizamento adventício

\section{ROOTING HARDWOODY CUTTINGS OF QUINCE (Cydonia oblonga) CULTIVARS TREATED WITH FLOROGLUCINOL}

\begin{abstract}
The quince belongs from the family Rosaceae. Now, it has been used as rootstock tree door-graft because it induce dwarf plants. The floroglucinol is a phenolic compost, which effects is by increased the auxine and that tends to induce and to increase hardwoody cuttings. The present work was carried out in a greenhouse with intermittent mist writh the objective to determine the best quince cultivars in relation to its capacity of rooting hardwoody cuttings, and the best floroglucinol concentration for the root induction. The cultivars Pineapple, Meliform, Prolonged, Radaelli, Portugal, Inta and MC were used. They were submitted to three treatments of different floroglucinol concentrations (zero, 1500 and $3000 \mathrm{mg}^{-L^{-1}}$ ). The cuttings with $12 \mathrm{~cm}$ and $1 / 2$ leaf in the superior part were conditioned in plastic boxes contends medium vermiculita. The experimental design used random blocks in the factorial arrangement ( $3 \times 7)$, with 3 repetition and 5 cuttings for replication ( 15 cuttings for treatments). The analyzed variables were determination of the percentage of rooting, number of roots and percentage of cuttings shottings. It was observed that, independently of the tested concentration, the floroglucinol, did not induce the rooting of hardwoody cuttings of the cultivars tested. Cultivar MC presented better percentage of rooting, number of roots and percentage of shottings.
\end{abstract}

Index terms: propagation, greenwood, rootstock, adventitious rooting

O marmeleiro (Cydonia oblonga) pertence à família Rosaceae. Atualmente, esta frutífera vem sendo utilizada, em outros países, como porta-enxerto preferencial da pereira, com o intuito de obter-se plantas de pequeno porte e rápida frutificação (Nogueira, 1985), além de proporcionar uniformidade aos pomares (Leite, 1992). O uso do marmeleiro como porta-enxerto clonal tem por objetivo resistência às condições adversas do solo, precocidade na frutificação, produtividade e, principalmente, controle do vigor da planta (Leite \& Denardi, 1992), devido sua característica ananizante (Simonetto \& Grellmann, 1988; Silva, 1997; Zecca, 1995); uma vez que os porta-enxertos adequados às condições de solos argilosos como, por exemplo, Pyrus calleryana e Pyrus betulaefolia são bastante vigorosos (Silva, 1997; Zecca, 1995).
Na cultura da macieira, o uso de porta-enxertos clonais tem controlado o vigor e proporcionado precocidade na frutificação (Leite, 1992). O adensamento do plantio de pereira, implicando número maior de plantas por área e maior produtividade, é de suma importância para o desenvolvimento desta cultura, visto que há grande potencial de expansão no Sul do Brasil, o que impulsionará a realização de estudos com portaenxertos adaptados e que apresentem afinidade com as diferentes cultivares (Silva, 1997).

Embora na fruticultura o uso de plantas enxertadas seja uma prática comum, ressalta-se a dificuldade relacionada à falta de afinidade entre enxerto e porta-enxerto, principalmente quando se trata de enxertia intergenérica como é o caso da pereira sobre o marmeleiro (Fachinello et al., 1999).

1 (Trabalho 156/2000). Recebido: 24/07/2000. Aceito para publicação: 05/09/2001.

2 Engenheiro Agrônomo, doutorando do PPGA, Área de Concentração Fruticultura de Clima Temperado, FAEM/UFPel, Cx. P. 354, 96010-900, Pelotas, RS. E-mail: ruffato@ufpel.tche.br

3 Engenheira Agrônoma, mestranda do PPGA, Área de Concentração Fruticultura de Clima Temperado, FAEM/UFPel, Cx. P. 354, 96010-900,

Pelotas, RS. E-mail: gemeyer@ufpel.tche.br

4 Engenheiro Agrônomo, Dr. Professor,, FAEM/UFPel, Cx. P. 354, 96010-900, Pelotas, RS. 
A utilização da estaquia, de acordo com Fachinello et al. (1995), apresenta algumas vantagens, de forma que plantas produzidas com porta-enxertos originários de estacas apresentam maior uniformidade do que plantas enxertadas sobre portaenxertos oriundos de sementes, são de baixo custo e de fácil execução.

Fachinello et al. (1995) afirmam que a utilização de reguladores de crescimento no enraizamento é uma prática largamente difundida, podendo, em muitas espécies de difícil enraizamento, viabilizar a produção de mudas através da estaquia. Hammatt (1994), apud Rufato et al. (1999), verificou que houve aumento no enraizamento de Prunus avium com AIB e floroglucinol. O floroglucinol induziu crescimento em considerável número de explantes, independentemente de sua capacidade de responder à auxina endógena. Rufato et al. (1999), em trabalho com estacas lenhosas de cultivares de pessegueiro (Capdebosq e Diamante), constataram que o floroglucinol, na concentração de $2234 \mathrm{mg} . \mathrm{L}^{-1}$, associado com AIB, na concentração de $2000 \mathrm{mg} . \mathrm{L}^{-1}$, aumentou significativamente o enraizamento pela influência no metabolismo da auxina.

O objetivo deste trabalho foi avaliar a influência do floroglucinol no enraizamento de estacas lenhosas de diferentes cultivares de marmeleiro.

O trabalho foi conduzido em telado com nebulização intermitente, no Departamento de Fitotecnia da Faculdade Eliseu Maciel, Universidade Federal de Pelotas, Pelotas-RS. As estacas foram coletadas de canteiros adjacentes ao local de condução do experimento. O experimento foi implantado em abril de 2000, sendo utilizadas, na sua maioria, cultivares de marmeleiro obtidas da Epagri de Caçador-SC.

Foram utilizadas estacas lenhosas das cultivares de marmeleiro Pineapple, Meliform, Alongado, Radaelli, Portugal, Inta e MC. As estacas foram preparadas com $12 \mathrm{~cm}$ de comprimento, sendo deixada meia folha na parte superior. Em seguida, efetuaram-se duas lesões na base das estacas, com aproximadamente $2 \mathrm{~cm}$, próximas a uma gema, com o objetivo de expor o câmbio. As estacas foram submetidas a três concentrações de floroglucinol (zero, 1500 e $3000 \mathrm{mg} . \mathrm{L}^{-1}$ ) durante 5 segundos e acondicionadas em caixas plásticas contendo vermiculita granulometria média.

O delineamento utilizado foi de blocos ao acaso, em arranjo fatorial ( $3 \times 7$ ), com 3 repetições e 5 estacas por parcela, totalizando 15 estacas por tratamento. Para análise estatística, utilizou-se o teste de Duncan $(\mathrm{a}=5 \%)$. As variáveis analisadas após 90 dias da implantação foram: percentagem de enraizamento, número de raízes e percentagem de estacas brotadas.

Embora existam resultados referenciados a respeito do uso de floroglucinol como indutor do enraizamento de estacas, neste trabalho, as médias observadas entre as cultivares não foram representativas, não havendo influência do floroglucinol na formação de raízes. Este resultado discorda dos de Rufato et al. (1999) que registraram efeitos significativos com administração de floroglucinol e de auxina (AIB). Da mesma forma, Zanol (1996), utilizando explantes de porta-enxerto de macieira cultivar Marubakaido in vitro, constatou percentagem significativa de enraizamento, influenciada pela utilização associada de AIB e floroglucinol.

Constatou-se que a cultivar MC apresentou $41,82 \%$ de estacas enraizadas (Figura 1), diferindo das outras seis cultivares

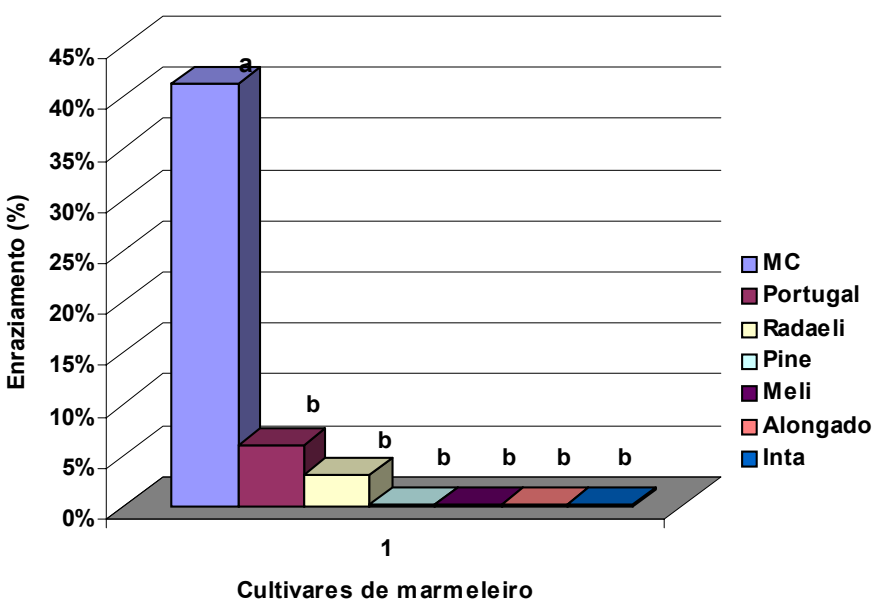

FIGURA 1 - Percentagem de enraizamento de estacas de diferentes cultivares de marmeleiro. Pelotas- RS, 2000.

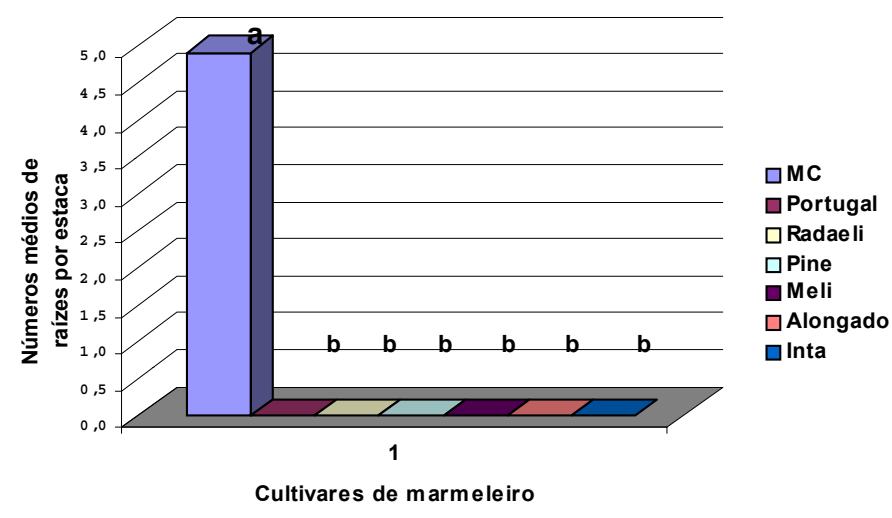

FIGURA 2 - Número de raízes de diferentes cultivares de marmeleiro. Pelotas- RS, 2000.

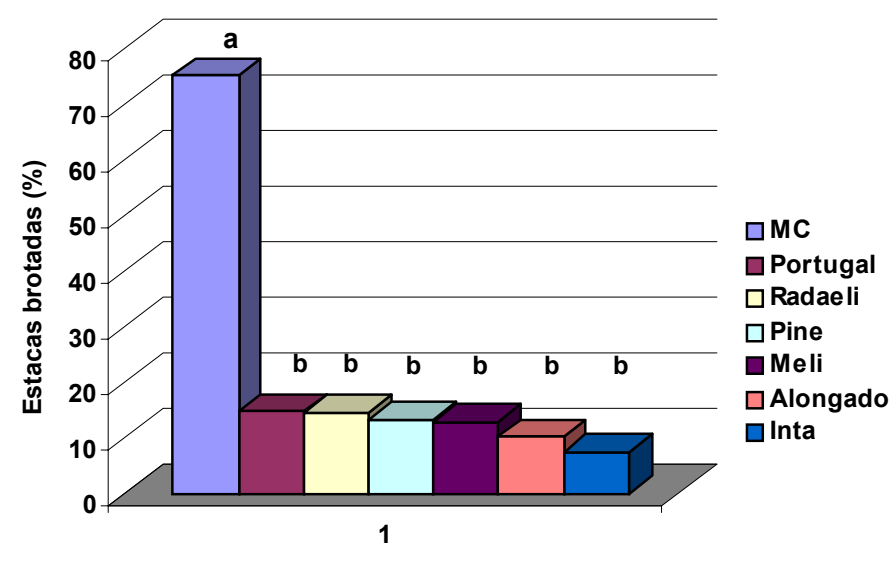

Cultivares de marmeleiro

FIGURA 3 - Percentagem de estacas brotadas de diferentes cultivares de marmeleiro. Pelotas- RS, 2000.

que formaram um grupo homogêneo de porcentagens bem inferiores. A cultivar MC, seleção pertencente ao grupo Anger, desenvolvido na Estação Experimental de East Malling, Inglaterra, propaga-se bem por estaquia com enraizamento em torno de $75 \%$ (Lombard \& Westwood, 1989 apud Leite, 1992).

A diferença de enraizamento entre cultivares de marmeleiro é evidenciada por Hepaksoy \& Unal (1995) que obtiveram 38\% de enraizamento para a cultivar Quince A e somente $0,67 \%$ para 
a cultivar Seker Gevrek. Diversos autores evidenciam a diferença no potencial genético de enraizamento existente entre cultivares de uma mesma espécie, o que justifica os resultados obtidos neste experimento. Fachinello et al. (1995) afirmam que a potencialidade de uma estaca formar raiz, é variável com a espécie e também com a cultivar. Entre espécies e até entre clones de uma mesma variedade, existem diferenças quanto à capacidade de enraizamento. As estacas de uma determinada espécie, como o pessegueiro, encontram variações no enraizamento de estacas entre variedades ou clones (Hartmann \& Brooks, 1958).

A cultivar MC foi significativamente superior quanto ao número de raízes (Figura 02) e percentual de estacas brotadas (Figura 03), registrando-se 75,24\%. Ressalta-se, portanto, a existência de uma relação direta entre as variáveis percentagem de enraizamento e percentual de estacas brotadas, mediante a semelhança nos resultados obtidos.

De acordo com os resultados observados, percebe-se a superioridade da cultivar MC sobre as demais, considerando sua capacidade de enraizamento, mesmo sem a presença de auxina. Embora o objetivo tenha sido somente o enraizamento, Baratta \& Raimondo (1988) constataram que a cultivar MC, quando utilizada como porta-enxerto de pereira, apresenta boa compatibilidade com as cultivares copas, quando comparados a porta-enxertos provenientes de macieira. Tal informação, acrescida dos resultados obtidos, aumenta a credibilidade no potencial desta cultivar para a produção de mudas de pereira, através do enraizamento de estacas lenhosas.

O floroglucinol, nas concentrações de 1500 mg.L $L^{-1}$ e 3000 $\mathrm{mg} . \mathrm{L}^{-1}$, não promove a indução do enraizamento de estacas lenhosas das cultivares Pineapple, Meliform, Alongado, Radaelli, Portugal, Inta e MC.

A cultivar MC apresenta melhor percentagem de enraizamento, número de raízes e número de brotações que as demais cultivares, independentemente do tratamento com floroglucinol.

\section{REFERÊNCIAS BIBLIOGRÁFICAS}

BARATTA, M B.; RAIMONDO, A. Prove d'innesto del nespolo Del Giappone su portinnesti clonali di cotogno e melo. I Portinnesti delle piante da fruto, Ferrara, v. 15-16, p. 13-16, 1998.

FACHINELLO, J.C.; HOFFMANN, A.; NACHTIGAL, J.C.; KERSTEN, E.; FORTES, G.R. de L. Propagação de plantas frutíferas de clima temperado. Pelotas: Editora e Gráfica UFPel, 1995. 179p.

FACHINELLO, J.C.; MUSACCHI, S.; ZUCCHERELLI, S.; SANSAVINI, S. Efeito da interação porta-enxerto copa no padrão isoenzimático de plantas de pereira. Revista Brasileira de Fruticultura, Cruz das Almas, v. 21, n. 3, p. 288-296, 1999.

HARTMANN, H. T.; BROOKS, R. M. Propagation of stockton morello cherry rootstock by softwood cuttings under mist sprays. Procedings of the American Society for Horticultural Science., Alexandria, v. 71, p. 127-134, 1958.

HEPAKSOY, S.; UNAL, A. Propagation of some quince varieties by hardwood cuttings. Ege Universitesi-Ziraat-FakultesiDergisi, v. 32, n. 1, 1995, p. 61-66.

LEITE, G.B. O uso do marmeleiro como porta-enxerto de pereira. Horti Sul, Pelotas, v.2, n.4, p.28-32, 1992.

LEITE, G.B.; DENARDI, F. Porta-enxertos para pereira; adaptação a algumas condições ambientais. Agropecuaria Catarinense, Florianópolis, v.5, n.2, p.47-49, 1992.

NOGUEIRA, D.J.P. Os porta-enxertos na fruticultura de clima temperado. Informe Agropecuário, Belo Horizonte, v.11, n.125, p.3-12, 1985.

RUFATO, L; ROSSI, A.; LOMBARDI, S.R.; RIBEIRO, E; KERTEN, E. Efeito de diferentes concentrações de floroglucinol no enraizamento de estacas lenhosas de duas cultivares de pessegueiro (Prunus persica L. Batsch) tratadas com AIB. Revista Brasileira de Fruticultura, Cruz das Almas, v. 21, n. 3, p. 297-300, 1999.

SILVA, E.S.B. Obtenção de mudas de pereira (Pyrus spp.) através da enxertia e enraizamento simultâneos. 1980. 90f. Dissertação (mestrado) - Universidade Federal de Pelotas, Pelotas, 1980.

SIMONETTO, P.; GRELLMANN, E. Pereira. Porta-enxertos e algumas cultivares. IPAGRO Informa, Porto Alegre, n.31, p.510,1988 .

ZANOL, G.C. Enraizamento in vitro do porta-enxerto Marubakaido (Malus prunifolia) influenciado pela exposição de períodos de escuro, concentrações de Ácido Indolbutírico e Floroglucinol. Dissertação (mestrado) - Universidade Federal de Pelotas, Pelotas, 1980.

ZECCA, A.G.D. Microenxertia, Enxertia de calo e enxertia de microestaca sobre calo, "in vitro", como método de determinação de incompatibilidade da Pereira (Pyrus ssp.) sobre Marmeleiro (Cydonia oblonga). 1995. 110f. Dissertação (mestrado) Universidade Federal de Pelotas, Pelotas, 1995. 